pivotal force that transformed Italian-American labor militancy from a transnational to a nationalistic focus. David Brundage examined the tension between Irish nationalism and Irish-American working-class activism. In comments, Dirk Hoerder cautioned that internationalist consciousness for workers seems to fragment immediately with the outbreak of war and that ideological transnationalism among radical leaders may be a wholly separate phenomenon.

The conference also made important connections between labor historians, the portrayal of public history, and activism. The second plenary session was devoted to current organizational concerns and included a forceful talk by Brad Markell of the UAW on transnational labor solidarity. At an earlier panel, Beverly Butler, in a creative multimedia presentation, explored the possibilities and limitations of labor history as public history.

The broad scope of research presented revealed many auspicious new directions for labor history, only a few of which can be reported here. Rather than moving toward synthesis, we appear to be in a period of creative ferment that suggests a range of intellectual and political challenges rather than pessimism for the future of the field.

\title{
Theories, Methods, and Concepts in Social and Cultural History: Report on the Social History Society Conference, York
}

\author{
Ann McCrum \\ University of Edinburgh
}

The January 1995 Social History Society conference opened with a plenary lecture by Carolyn Steedman (University of Warwick) entitled "Linguistic Encounters of the Fourth Kind." The major focus of the paper was the adoption of the term "language" to mean "discourse" in the Foucauldian sense and therefore the neglect of language in the linguistic sense. The vehicle for the analysis was a case study of a memoir written in 1881 by a retired policeman in his sixties. In the middle of the memoir there is a move from simple one-to-one articulation to an analysis of qualitative material using such concepts as capital and production. As the writing departs from a routine personal description and becomes a debate with the author himself, Steedman suggested that the transition is the result of a significant encounter with "culture," for which the act of writing is the catalyst. Thus the relative perspective of the memoir writer's vision is in the narrative itself, which carries its own message in the form or medium of the language used. 
Patrick Joyce (Manchester University), Arthur Marwick (Open University), and Ludmilla Jordanova (University of York) were also concerned with ideas of discourse, experience, agency, and cultural context. Joyce expounded on the need for historians to explore their understanding of "social" and "society," which, he argued, are discursive or culturally produced and as such are creations of modernity. A postmodern approach in identifying the normative nature of such terms highlights the importance of access to narrative in historical analysis. Marwick responded directly to Joyce's argument with an exposition on the historian as craftsman. His perspective stressed the importance of skills in qualitative analysis that are part of a discipline and the need for that discipline to be upheld in order to encourage continuity within the study of history and to further the reproduction of this kind of experience. After these general perspectives, Jordanova addressed the more particular subject of difficulties in defining cultural history and illustrated possible approaches with examples from the history of science and medicine, art history, and the history of music. Her paper pointed out the problems that can arise when studying areas where little previous work has been done and there is a minimum of discourse to shape the project.

Gareth Stedman Jones (Cambridge) gave another plenary paper on Carlyle, Engels, and the representation of the working classes, developing the contextual elements in the German influence in Carlyle's life and work. The strong imagery of Carlyle's writing, particularly the Biblical references, was powerfully conveyed and the links to popular culture in Carlyle's influence on Victorian novelists were clearly set out. The threads of the argument were drawn together in an exploration of the importance of symbol as a carrier of culture and the resulting possibility that symbols have a seminal role in the growth of intolerance.

The conference dinner was followed by a speech entitled "Mixture and Analysis in the Seventeenth Century" by Natalie Zemon Davis from Princeton but currently at Oxford. This encapsulated ideas of identity, context, cross-cultural influences, modernity, structure, and theory within a narrative about three individual case studies of seventeenth-century women. The marrying of conflicting influences in the tale told by Davis resulted, in two of the cases, in a new "mixture" and provided a powerful metaphor for the validity of cross-cultural influences in the study of history, producing a new product from old sources.

The third and final plenary lecture by David McCrone (University of Edinburgh) on "Constructing National Identities: Reflections from a Small Nation" highlighted the problems of definition with particular reference to the term nation-state: Its widespread use obscures the fact that nation and state are distinct entities in Britain, where the state combines four different nations. The process by which the idea of "Britishness" was constructed and reconstructed, from the eighteenth- and nineteenth-century imperial power, to the twentieth-century upholder of democracy, and then to the 
"socialist" Britain of the welfare state, gives some idea of the possibility of alternative versions submerged by issues of power, class, politics, gender, and race. This paper echoed much of the work of the conference in highlighting the need for contextual analysis that illuminates underlying cultural discourse and the identities it produces.

There were five nonplenary sessions, each offering three alternatives with three speakers in each alternative. The first four sessions had as their broad themes current conceptual issues as seen through a variety of different historical disciplines: cultural issues, theory, sources, and analysis. The fifth and last session offered papers on marriage, children, and religion; nations and tradition; and class in Britain. Among the approaches prevalent in these sessions were those based in gender history and those whose perspectives include the postimperial or postcolonial. There were some interesting reports in a number of different sessions on the use of people's own life histories as told to the interviewer and the importance of the narrative itself in analysis.

A common factor in most of the sessions was the use of case studies to illustrate the use of theory in the practice of history. To give just one example, the last session, "Class in Britain," had a paper by Ruth Grayson (Sheffield Hallam University) and Alan White (University of East London) whose empirical research shows that the "little masters" of nineteenth-century Sheffield were slipping into the status of outworkers at the mercy of the factor who controlled access to external markets. Grayson and White used this conclusion as an illustration of Roemer's thesis that a class structure can just as easily result from exploitation in the capital market as from exploitation in the labor market.

This conference offered a very large number of papers of a high standard which, despite their diversity, remained centered on the main theme of theory, methods, and concepts in social and cultural history and thus facilitated discussion and debate among historians of widely differing interests. 